\title{
Avranches - Le Grand Doyenné
}

$n^{\circ} 3353$

\section{David Nicolas-Méry}

\section{(2) OpenEdition}

Journals

Édition électronique

URL : http://journals.openedition.org/adlfi/16692

ISSN : 2114-0502

Éditeur

Ministère de la culture

Référence électronique

David Nicolas-Méry, "Avranches - Le Grand Doyenné », ADLFI. Archéologie de la France - Informations [En ligne], Basse-Normandie, mis en ligne le 26 février 2016, consulté le 21 avril 2019. URL : http:// journals.openedition.org/adlfi/16692

Ce document a été généré automatiquement le 21 avril 2019

(c) Ministère de la Culture et de la Communication, CNRS 


\title{
Avranches - Le Grand Doyenné
}

$n^{\circ} 3353$

\author{
David Nicolas-Méry
}

Lien Atlas (MCC) :

http://atlas.patrimoines.culture.fr/atlas/trunk/index.php?

ap_theme=DOM_2.01.02\&ap_bbox=-1.377;48.675;-1.336;48.702

1 Dans le cadre des recherches qui se poursuivent au Grand Doyenné, un sondage archéologique a été réalisé, en octobre 2013, afin de vérifier la présence de structures disparues, côté cour, au sud de l'édifice.

2 À l'époque de sa construction, au XII ${ }^{\mathrm{e}}$ s., le Grand Doyenné est un bâtiment constitué par un volume unique qu'occupe une vaste salle d'apparat accessible de plain-pied depuis la cour située au sud et reposant sur une salle basse voûtée prenant appui contre la pente naturelle septentrionale de la ville haute d'Avranches. Or, à l'instar de quelques édifices contemporains, en Normandie et en Angleterre, il était possible de supposer que ce vaste volume de $230 \mathrm{~m}^{2}$ possédait, au sud, contre sa façade, un "bas-côté », c'est-à-dire une sorte de galerie de dégagement couverte par un toit en appentis.

3 Le sondage a consisté en une tranchée perpendiculaire à la façade moderne, reconstruite en 1762, et a permis d'observer divers niveaux d'occupation du site: la présence du pavage du XVIII siècle, immédiatement situé sous les graviers de la cour; puis, immédiatement sous le lit de sable de ces pavés, une couche composée de terre argileuse, garnie de tessons et de déchets alimentaires, correspondant à la destruction d'un mur imposant situé à 5 mètres de la façade du Grand Doyenné.

4 Parfaitement parallèle à la façade, ce mur est très imposant: il mesure $1,37 \mathrm{~m}$ en épaisseur et ses caractéristiques sont semblables aux maçonneries médiévales du monument, confirmant ainsi qu'il appartient bien à une même phase de construction. Cette structure est vraisemblablement le mur extérieur du bas-côté envisagé. Les fondations du mur ont été repérées à une soixantaine de centimètres seulement sous le sol de la cour, et, à leur contact, un sol damé a pu être repéré. 
5 Ce sondage a donc permis d'étayer sérieusement l'hypothèse selon laquelle le Grand Doyenné se développait bien originellement vers le sud; si la salle d'apparat possédait $230 \mathrm{~m}^{2}$ au sol, il faut à présent envisager qu'un bas-côté d'environ $100 \mathrm{~m}^{2}$ la complétait au sud.

INDEX

Index géographique : Basse-Normandie, Manche (50), Avranches

Index chronologique : Moyen Âge, Temps Modernes

operation Sondage (SD)

\section{AUTEURS}

DAVID NICOLAS-MÉRY

$\mathrm{COL}$ 